\title{
Treating young patients with breast cancer
}

\author{
The evidence suggests that all should be treated with adjuvant therapy
}

Papers $\mathrm{p} 474$

BMJ 2000;320:457-8
B reast cancer is uncommon in young women, but when it strikes it has a devastating effect on patients and their families. Several studies have shown that women who develop breast cancer in their 20s and 30s have worse survival and more biologically aggressive cancers with higher rates of proliferation and lymphovascular invasion and lower levels of oestrogen receptors than older patients with cancers of the same stage. ${ }^{1}$ Yet despite their apparently worse survival, younger women get more benefit from chemotherapy than older women. An overview of randomised trials showed that patients with operable breast cancer aged under 40 have a $37 \%(\mathrm{SD} 7)$ proportional reduction in the odds of recurrence and a 27\% (SD 8 ) reduced risk of death with adjuvant chemotherapy compared with reductions of 20.3\% (SD 2.6) and 11.3\% (SD 2.9) respectively for women aged 50-69. ${ }^{2}$ These proportionally greater benefits from adjuvant chemotherapy seem to be independent of node status.

There has been an increasing trend to give chemotherapy to almost all young patients with operable breast cancer regardless of lymph node status. ${ }^{3}$ This change in practice is supported by data from a study in Denmark by Kroman et al in this week's $B M J$ (p 474). ${ }^{4}$ Among 867 patients aged under 35 they identified 315 who were considered low risk (based on tumour size $<5 \mathrm{~cm}$, no skin invasion, clear margins of excision, and negative lymph nodes) and who did not receive chemotherapy. These younger women had a significantly increased risk of dying of breast cancer than older women with similar stage cancers. Yet an increased risk of death with decreasing age was not seen in women considered high risk who received adjuvant chemotherapy. These findings are consistent with the St Gallen consensus guidelines, which state that no patient aged under 35 should be truly considered low risk. ${ }^{4}$

Adjuvant chemotherapy in younger women with breast cancer is cost effective in terms of cost per quality adjusted life year gained in patients with both node negative and node positive disease. ${ }^{5}$ Randomised trials have not so far identified a subgroup of younger women who do not derive some benefit from adjuvant chemotherapy, although the size of this benefit varies considerably and is directly related to the risk of recurrence and mortality. Whether an individual patient chooses to receive adjuvant chemotherapy depends on the ratio of benefits to risks of treatment-which for some cancers is very small.

What adjuvant chemotherapy regimen should these young women with breast cancer receive? Most patients in the Danish study were treated with cyclophosphamide, methotrexate, and fluorouracil (CMF) chemotherapy, the dose and schedule of which have been criticised. ${ }^{6}$ The overview showed that, compared with this regimen, anthracycline based chemotherapy regimens yielded significantly lower rates of recurrence and marginally but significantly improved rates of survival. ${ }^{2}$ For this reason anthracycline based adjuvant regimens are currently the most widely used in younger women. Studies in women with high risk breast cancer have shown that four cycles of adriamycin followed by eight of cyclophosphamide, methotrexate, and fluorouracil produce greater benefits than alternating these agents. ${ }^{7}$ More recently sequencing four cycles of adriamycin plus cyclophosphamide and four cycles of paclitaxel has shown improved survival compared with adriamycin plus cyclophosphamide alone. ${ }^{8}$ This sequence of anthracyclines and taxanes may become the adjuvant therapy of choice, at least in high risk younger women if subsequent randomised trials confirm its benefit over other regimens. High dose adjuvant chemotherapy and autologous stem cell rescue provides little or no added benefit over standard adjuvant regimens, even for younger women with high risk disease, and should not be used outside trials.

Although a greater proportion of breast cancers in young women are oestrogen receptor negative, more than half express some level of oestrogen receptor. Tamoxifen given for five years produces similar benefits in both premenopausal and postmenopausal women. ${ }^{9}$ Side effects are commoner in young women, but the increase in the incidence of thromboembolism and endometrial cancer occurs predominantly in postmenopausal women. ${ }^{10}$ In premenopausal women with oestrogen receptor positive breast cancers a combination of gonadotrophin releasing hormone analogues and tamoxifen seems to be better tolerated and has been reported to significantly reduce recurrence compared with cyclophosphamide, methotrexate, and fluorouracil. ${ }^{11}$ The combination of gonadotrophin releasing hormone analogues and tamoxifen also produces more benefit than tamoxifen alone in patients with oestrogen receptor positive breast cancers after anthracycline based chemotherapy. ${ }^{12}$ These data suggest that adjuvant hormonal therapy should be considered in all young women whose tumours express any level of oestrogen receptors.

Young women are at increased risk of local recurrence, contralateral disease, and systemic recurrence, so any systemic therapy needs to be combined 
with optimal local treatments. ${ }^{12}$ In some young women with a strong family history of bilateral disease bilateral mastectomy for a small localised breast cancer should be considered and discussed with the patient. Younger women with breast cancer suffer much greater disruption to their lives than older women and have a higher incidence of depression and disease specific intrusive thoughts.

Current evidence suggests that survival of women with breast cancer is improved if they are treated in major centres by multidisciplinary teams. These centres provide the ideal environment for providing support for patients and their families and exploring through clinical trials the most effective adjuvant therapy for individual patients and their cancer.

J M Dixon consultant surgeon and senior lecturer Edinburgh Breast Unit, Western General Hospital, Edinburgh EH4 2XU

(jmd@wght.demon.co.uk)

G Hortobagyi professor of medicine

Department of Breast Medical Oncology, Texas Medical Center, Houston, Texas 77030, USA

1 Nixon AJ, Neuberg D, Hayes DF, Gelman R, Connolly JL, Schnitt S et al. Relationship of patient age to pathological features of the tumor and prognosis of patients with stage I or II breast cancer. J Clin Oncol $1994 ; 12: 888-94$
2 Early Breast Cancer Trialists' Collaborative Group. Polychemotherapy for early breast cancer: an overview of the randomised trials. Lance 1998;352:930-42.

3 Goldhirsch A, Glick JH, Gelber RD, Senn HJ. Meeting highlights: International consensus panel on the treatment of primary breast cancer. JNCI 1998;90:1601-8.

4 Kroman N, Jensen M-B, Wohlhardt J, Mourisden HT, Andersen PK, Melbye M. Factors influencing the effect of age on prognosis in breast cancer: population based study. BMJ 2000;320:474-9.

5 Smith TJ, Hillner BE. The efficacy and cost-effectiveness of adjuvant therapy in early breast cancer in premenopausal women. J Clin Oncol 1993;11:771-6.

6 Goldhirsch A, Coates AS, Colleoni M, Gelber RD. Radiotherapy and chemotherapy in high risk breast cancer. Letter to the editor. Lancet 1998;338:330.

7 Bonadonna G, Zambetti M, Valagussa P. Sequential or alternating doxorubicin and CMF regimens in breast cancer with more than 3 positive nodes: 10 year results. JAMA 1995;273:542-7.

8 Henderson IC, Berry D, Demetri G, Cirrincione L, Goldstein S, Martino $\mathrm{S}$, et al. Improved disease-free (DSF) and overall survival (OS) from the addition of sequential paclitaxel (T) but not from the escalation of doxorubicin (A) dose level in the adjuvant chemotherapy of patients (PTS) with node-positive primary breast cancer (BC). Proc Am Soc Clin Oncol 1998;17:101a

9 Early Breast Cancer Trialists' Collaborative Group. Tamoxifen for early breast cancer: an overview of the randomised trials. Lancet 1998:351:1451-67.

10 Day R, Ganz BA, Costantino JS, Cronin WN, Wicherhen DL, Fisher B. Health-related quality of life and tamoxifen in breast cancer prevention: a report from the National Surgical Adjuvant Breast and Bowel Project B-1 study.J Clin Oncol 1999;70:2659-69.

11 Jakesz R, Gnant M, Hausmaninger H, Samonigg H, Kubista E, Steindorfer $\mathrm{P}$, et al. Combination goserelin and tamoxifen is more effective than $\mathrm{CMF}$ in premenopausal patients with hormone-responsive breast cancer study group (ABCSG). Breast Cancer Research and Treatment 1999;57:25.

12 Overgaard M, Hansen PS, Overgaard J, Rose C, Andersson M, Bach F, et al. Post-operative radiotherapy in high-risk premenopausal women with breast cancer who receive adjuvant chemotherapy. $N$ Engl J Med 1997:337:949-55

\section{Is CS gas dangerous?}

\section{Current evidence suggests not but unanswered questions remain}

$\mathrm{C}$ $\mathrm{S}$ gas (2-chlorobenzylidene malononitrile) is one of the most commonly used tear gases in the world. Law enforcement agencies have found this agent invaluable when faced with combative suspects, for riot control, and for alleviating hostage and siege situations. They use it to help control individuals or groups without the need for lethal force. The chemical was used for crowd control as early as the 1950 s, but not until the mid-1960s did it come into common use in several countries. In Britain there has been persistent concern about the use of CS gas in the media, numerous complaints to the Police Complaints Authority, and an editorial two years ago in the Lancet that called for a moratorium on the use of CS tear gas. ${ }^{1}$ This editorial was unusual in calling for a moratorium on an agent used widely for decades with little data on permanent damage. Nevertheless, it did correctly identify the need for some further studies, as did a report recently commissioned by the British government. ${ }^{2}$

At standard daily temperatures and pressures CS forms a white crystal with a low vapour pressure and poor solubility in water. CS aerosols thus act as a "powdered barb" with microscopic particles which are potent sensory irritants becoming attached primarily to moist mucous membranes and moist skin. The eye is the most sensitive organ in riot control because CS causes epiphora, blepharospasm, a burning sensation, and visual problems. Coughing, increased mucous secretion, severe headaches, dizziness, dyspnoea, tightness of the chest, difficulty breathing, skin reactions, and excessive salivation are common. The onset of symptoms occurs within 20 to 60 seconds, and if the exposed individual is placed in fresh air these findings generally cease in 10 to 30 minutes. In the main the medical literature supports the safety of CS gas. ${ }^{3-5}$

Significant reactions have been reported, ${ }^{6-8}$ which may be a result of the way the gas is used. In the heat of a crisis both sides may overreact by excessive use of this agent (the police using too much, rioters throwing canisters back), or the combatants may not leave the area and thus remain exposed and away from the gas's natural antidote-fresh air. In over 30 years of active use of $1 \%$ CS gas no lawsuits for damages have been awarded in the litigious environment of the United States. In Britain, however, the spray used by police contains 5\% CS in methyl isobutyl ketone (MIBK).

There are no scientific data on the relative safety of $1 \%$ versus $5 \%$ CS. This is hard data to obtain, since most damage is from aerosol fired at close range, and over half the injuries are "self inflicted" in the sense that the victims voluntarily expose themselves to the gas and remain exposed. Many suspect that the most significant side effects occur in those individuals most active in continuing civil disobedience.

The British Department of Health, with the support of the Home Office, asked three of its advisory committees (on Toxicity, Mutagenicity, and Carcinogenicity of Chemicals in Food; Consumer Products; and the Environment) to study the use of CS spray as a chemical incapacitant because of public health concerns. The report, released last year, stated that many data were available on the toxicity of CS and, to a 